\title{
Interleukin-18 and its three gene polymorphisms relating to allergic rhinitis
}

\author{
Sarka Sebelova $\cdot$ Lydie Izakovicova-Holla $\cdot$ \\ Andrea Stejskalova $\cdot$ Marcel Schïller · \\ Vladimir Znojil · Anna Vasku
}

Received: 5 August 2006/ Accepted: 7 November 2006/Published online: 25 January 2007

(C) The Japan Society of Human Genetics and Springer 2007

\begin{abstract}
The study aimed to examine an association of three different single nucleotide polymorphisms (SNPs) of the IL-18 gene (-607 C/A, $-137 \mathrm{G} / \mathrm{C}$ and $-133 \mathrm{C} / \mathrm{G})$ on chromosome $11 \mathrm{q} 22$ with allergic rhinitis (AR). Genotyping for the SNPs was performed using 539 patients with AR and 312 healthy control volunteers. Positivity to the skin prick test for the fungus Alternaria sp. in patients with $\mathrm{AR}$, and $\mathrm{IgE}$ levels according to particular genotypes of selected SNPs, were also determined. There were no significant differences in the distribution of single IL-18 alleles or genotypes between controls and AR patients. However, frequencies of combined IL-18 genotypes arising from combinations of the three common polymorphisms $(-607,-137$ and -133$)$ were significantly different between both groups $\left(P=0.009, P_{\text {corr }}<0.05\right.$, $\mathrm{OR}=5.35,95 \%$ CI: $1.9-15.2)$. There was a marginally significant association of the IL-18-607 variant with IgE levels $(P=0.05)$ in patients, but not in the case of the other SNPs. Patients allergic to Alternaria, but not those allergic to other antigens, showed a significant association with the IL-18-607 polymorphism $\left(P=0.0037, P_{\text {corr }}<0.05\right)$. Results suggest that IL-18 gene variants may be one of the factors participating in the pathogenesis of AR or its intermediary phenotypes.
\end{abstract}

S. Sebelova $(\bowtie) \cdot$ L. Izakovicova-Holla

A. Stejskalova · M. Schüller · V. Znojil .

A. Vasku

Department of Pathophysiology, Faculty of Medicine,

Masaryk University, Komenského nám. 2,

66243 Brno, Czech Republic

e-mail: ssebelova@chello.cz
Keywords Allergic rhinitis - Hay fever - IL-18 gene · Gene polymorphism · Atopic diseases

$\begin{array}{ll}\text { Abbreviations } \\ \text { AR } & \text { Allergic rhinitis } \\ \text { SNP } & \text { Single nucleotide polymorphism } \\ \text { IL-18 } & \text { Interleukin-18 } \\ \text { AEDS } & \text { Atopic eczema dermatitis syndrome } \\ \text { OR } & \text { Odds ratio } \\ \text { Th1, Th2 } & \text { T helper cells } 1,2 \\ \text { ALT } & \text { Alternaria } \text { sp. }\end{array}$

\section{Introduction}

Interleukin-18 (IL-18) has become recognized as an important regulator of innate and acquired immune responses and is expressed at sites of chronic inflammatory disease. Positive association studies of polymorphisms in IL-18 with different diseases have underlined the involvement of this cytokine in pathogenetics processes. Indications exist that polymorphisms in cytokine genes involved in the regulation of T helper cells (Th1/Th2) balance may contribute to the allergic phenotype. Allergic diseases such as asthma, allergic rhinitis (AR) (hayfever) and atopic eczema (AE) are a major cause of morbidity worldwide and have been increasing in frequency (Beasley 1998). AR is a heterogeneous disorder that despite its high prevalence is often undiagnosed (Skoner 2001). However, as a Th2-mediated disease, AR is determined by an interaction of environmental and genetic factors and biologically characterized by an imbalanced Th1/Th2 
immune response and elevated $\operatorname{IgE}$ levels against inhalant allergens.

The prevalence of AR in various countries, for example, ranges from 3-19\% (Skoner 2001). It is a very common human multifactorial disease involving inflammation of the mucous membranes of the nose, eyes, Eustachian tubes, middle ear, sinuses and pharynx. Although the nose is invariably involved, other organs as mentioned may be affected in certain individuals. While inflammation of the mucous membranes is characterised by a complex interaction of inflammatory mediators, it is triggered ultimately by an immunoglobulin $\mathrm{E}$ (IgE)-mediated response to allergens. The pleiotropic role of IL-18 in Th1 and Th2 differentiation is known to be controlled by the cytokine milieu. IL-18 not only induces Th1 cytokines, such as INF- $\gamma$, but also stimulates Th2 cytokine production, IgE levels and eosinophil recruitment, such as in allergic inflammation (Nakanishi et al. 2001).

The gene for IL-18 is located at chromosome 11q22.2-22.3, a region that has been previously linked to atopy-related traits (Koppelman et al. 2002). It is composed of six exons, and its expression is regulated by two distinct promoters upstream of exon 1 (promoter 1) and exon 2 (promoter 2), with the start codon located in exon 2 (Kalina et al. 2000). Recently, genetic variants in the IL-18 gene have been associated with increased risk of atopy and asthma (Izakovicova Holla 2003, Imboden et al. 2006), but unfortunately relatively few studies have been undertaken on the association between IL-18 single nucleotide polymorphisms (SNPs) and other allergic diseases, particularly AR. Kruse et al. (2003) described an SNP (-920[t/c], -133[c/g] and $-132[\mathrm{a} / \mathrm{g}])$ in the promoter region of IL-18 in AR patients and, moreover, found that total $\mathrm{IgE}$ levels and response to specific allergens differed according to the presence of this IL-18 polymorphism. Novak et al. (2005) suggest that SNPs in the IL-18 gene might be involved in the development of $\mathrm{AE}$ by contributing to a functional dysregulation of IL-18 production in vivo. Imboden et al. (2006) consider the G-allele of the IL18 promotor variant $(-137 \mathrm{G} / \mathrm{C})$ to be an important genetic determinant involved in the development of atopic asthma. One of the most recent studies (Lee et al. 2006) shows that the A allele in the IL-18/-607 $(\mathrm{C} / \mathrm{A})$ gene promoter region may be involved in the development of AR in the Korean population. In our study, we focused on three gene polymorphisms of the IL-18 gene (-607 C/A, $-137 \mathrm{G} / \mathrm{C}$ and $-133 \mathrm{C} / \mathrm{G})$ relating to $\mathrm{AR}$ as well as in combination with other allergic diseases, such as asthma or eczema, in a Czech population. We also evaluated whether there is an association between intermediary phenotypes of AR (such as positivity to the skin prick tests and total $\operatorname{IgE}$ levels) and aforementioned polymorphisms (so-called case-only study).

\section{Materials and methods}

\section{Subjects}

In total, 539 patients with $\mathrm{AR}$ and 312 non-atopic healthy volunteers were recruited from different allergologic clinics and from outpatient clinics of general practitioners in the Czech Republic during the years 2000-2005. A combination of both seasonal AR patients as well as perennial AR patients were recruited into the patient group. Patients in the study group were recruited from a relatively small geographic region of South Moravia in the Czech Republic. All patients were examined in as healthy a condition as possible, that is, before the start of the season in the case of seasonal AR patients or when they were without perceived health problems in the case of patients with perennial AR. Moreover, since they were examined by prick tests and measurement of IgE levels during the dormant period of the disease, the majority of subjects selected were not on any medication or undergoing therapy.

All subjects were selected using a detailed questionnaire, considering lifetime symptoms suggestive of asthma, rhinoconjunctivitis and AE/dermatitis syndrome (AEDS), together with additional questions regarding symptoms and therapy as well as other diseases.

The diagnosis of AR was based on a typical history of allergic symptoms of either perennial or seasonal rhinitis or both and the diagnostic test for IgE-mediated allergy (Van Bousquet et al. 2001). Concomitant asthma diagnosis was based on the following criteria: (1) current diagnosis of asthma according to the physician's record, (2) symptoms and (3) use of antiasthma medication. The diagnosis and classification of the clinical severity of asthma was established according to the Global Initiative for Asthma guidelines (NHBLI/ WHO 2002). The AEDS was defined according to the diagnostic criteria for AE initially proposed by Hanifin and Rajka (1980). Atopy was defined as (1) the presence of positive skin test reaction $(\geq 3 \mathrm{~mm}$ greater than the reaction to saline) to one or more of the common allergens (house dust mite, common mixed grass and tree pollens, mixed molds, cat and dog dander, together with histamine and normal saline as positive and negative controls, respectively), and/or (2) raised specific serum IgE levels $(>0.35 \mathrm{kU} / \mathrm{l}$ by AlaSTAT test, DPC Biermann, Bad Nauheim, Germany) produced in 
response to one or more of the common allergens including Dermatophagoides farinae, grass pollens, animal danders and molds), and/or (3) raised total serum IgE levels above normal values $(>100 \mathrm{IU} / \mathrm{ml}$ in non-smoking adults measured by the nephelometric test, Dade-Behring, Mannheim, Germany) as described previously (Buckova et al. 2002). Many fungi are seasonal and are monitored by services that measure the levels and nature of pollen. Of these, the most frequently occurring in the Czech Republic are Epicoccum, Stemphylium, Alternaria and Cladosporium. (http://www.tigis.cz/alergie/aler104/07.htm, in Czech, abstract in English) For this reason the positivity test for Alternaria sp. is involved in the standard skin prick test.

A subgroup of patients also underwent spirometric assessment to measure their forced expiratory volume in $1 \mathrm{~s}$ (FEV1), forced vital capacity (FVC) and peak expiratory flow (PEF).

Blood samples were collected and processed by standard universal protocols. The study was approved by the Committee for Ethics of the Medical Faculty, Masaryk University Brno, the Czech Republic, and informed consent was obtained from all participants, in line with the Helsinki declaration, before inclusion in the study.

\section{Methods}

Genomic DNA was isolated from peripheral blood by standard protocol (http://www.genome.ou.edu/protocol_ book/protocol_partIII.html\#III.H) and archived in the DNA bank in the Department of Pathophysiology, Faculty of Medicine, Masaryk University, Brno, Czech Republic. PCR-RFLP (restriction fragment length polymorphism) analysis for genotyping was performed with mutated primers, introducing the site for restriction in the case of SNP IL18/-133 C/G. However, in the case of both SNP IL-18/-607 and SNP IL-18/-137, so-called allelic specific primers were used (see
Table 1). In all reactions, PCR was performed in $15-\mu 1$ volumes consisting of DNA $50 \mathrm{ng}$, dNTP $250 \mathrm{mM}$, $\mathrm{MgCl}_{2} 50 \mathrm{mM}, 10 \times$ buffer (DYNEX), Taq polymerase $1 \mathrm{U} / \mu \mathrm{l}$ (DYNEX) and $0.2 \mathrm{mM}$ of primers. The fragments were resolved on $2 \%$ agarose gel. Genotyping was performed blind to the phenotypes. Restriction analysis was conducted in duplicate, and SNPs were segregated correctly.

\section{Statistical analysis}

Comparisons of the allele frequencies of selected IL-18 SNPs between the AR patients and controls were carried out using the Fisher exact test. $\chi^{2}$ analysis was used to test for deviation of the genotype distribution from Hardy-Weinberg equilibrium and for a comparison of differences in genotype combinations among groups. The Kruskal-Wallis ANOVA test was used for the evaluation of total IgE levels. Where appropriate, Bonferroni correction was applied to adjust the $\alpha$ level according to number of independent comparisons to an overall value of 0.05 . Adjusted $P$ values are denoted as $P_{\text {corr; }} P_{\text {corr }}<0.05$ was considered significant. Contingency table analysis, odds ratio (OR), 95\% confidence intervals and significance values were estimated with the use of the program package Statistica v 6.0 (Statsoft Inc., Tulsa, U.S.A.).

\section{Results}

A total of 851 subjects were included in this study. Characterisation of the study population is given in Table 2. The allele and genotype frequencies of the AR and control groups are shown in Table 3. All of these loci were in Hardy-Weinberg equilibrium in the control group. No significant differences were observed between both groups in terms of C and A (-607), G and $\mathrm{C}(-137)$ or $\mathrm{C}$ and $\mathrm{G}(-133)$ allele or genotype frequencies $(P>0.05)$.
Table 1 List of primers used for PCR-RFLP analysis

\begin{tabular}{|c|c|c|c|}
\hline Polymorphism & Primer & $\begin{array}{l}\text { Anneling } \\
\text { temperature }\end{array}$ & Enzyme \\
\hline Promoter 1, -137 & $\begin{array}{l}\text { 5'-AGGAGGGCAAAATGCACTGG-3'; } \\
\text { 5'-CCAATAGGACTGATTA-3' } \\
\text { 5'-CCCCAACTTTTACGGAAGAAAAG-3'; } \\
\text { 5'-CCCCAACTTTTACGGAAGAAAAC-3' }\end{array}$ & $68^{\circ} \mathrm{C}, 62^{\circ} \mathrm{C}$ & - \\
\hline Promoter $2,-133$ & 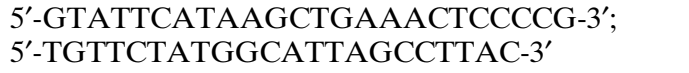 & $53^{\circ} \mathrm{C}$ & SmaI \\
\hline Promoter 1, -607 & $\begin{array}{l}\text { 5'-TAACCTCATTCAGGACTTCC-3'; } \\
\text { 5'-CTTTGCTATCATTCCAGGAA-3'; } \\
\text { 5'-GTTGCAGAAAGTGTAAAAATTATTAA-3'; } \\
\text { 5'GTTGCAGAAAGTGTAAAAATTATAC-3' }\end{array}$ & $64^{\circ} \mathrm{C}, 57^{\circ} \mathrm{C}$ & - \\
\hline
\end{tabular}


Table 2 Characterisation of the study population

\begin{tabular}{|c|c|c|c|c|c|c|c|c|c|c|}
\hline & \multirow[t]{2}{*}{$N$} & \multirow[t]{2}{*}{ Percentage } & \multicolumn{2}{|c|}{ Female } & \multicolumn{2}{|l|}{ Age } & \multicolumn{2}{|c|}{ Male } & \multicolumn{2}{|l|}{ Age } \\
\hline & & & $n$ & Percentage & (years) & $\pm \mathrm{SD}$ & $n$ & Percentage & (years) & $\pm \mathrm{SD}$ \\
\hline All & 851 & & 425 & 50 & 37 & 14.77 & 426 & 50 & 31 & 14.04 \\
\hline Non-atopic & 312 & 36.66 & 153 & 18 & 32 & 16.75 & 159 & 18.7 & 38 & 16.15 \\
\hline Rhinitis only & 247 & 29.02 & 135 & 15.86 & 35 & 13.49 & 112 & 13.16 & 29 & 12.21 \\
\hline Rhinitis + asthma & 140 & 16.45 & 70 & 8.23 & 37 & 11.92 & 70 & 8.23 & 29 & 11.09 \\
\hline Rhinitis + eczema & 55 & 6.47 & 32 & 3.76 & 29 & 8.67 & 23 & 2.7 & 23 & 7.19 \\
\hline Rhinitis + asthma + eczema & 97 & 11.40 & 35 & 4.11 & 32 & 13.52 & 62 & 7.28 & 25 & 7.83 \\
\hline
\end{tabular}

Table 3 Genotype distributions and allele frequencies of the IL-18 gene polymorphisms in allergic rhinitis (AR) patients and controls

\begin{tabular}{|c|c|c|c|c|c|c|c|}
\hline \multirow[t]{2}{*}{ Allele } & \multicolumn{3}{|c|}{ Control $(n=312)$} & \multicolumn{3}{|c|}{ Allergic rhinitis $(n=539)$} & \multirow[t]{2}{*}{$P$ value } \\
\hline & $n$ & Percentage & Frequency & $n$ & Percentage & Frequency & \\
\hline \multicolumn{8}{|c|}{ IL-18 SNP (-607 C/A) } \\
\hline AA & 37 & 11.8 & 0.118 & 72 & 13.4 & 0.134 & 0.442 \\
\hline $\mathrm{AC}$ & 164 & 52.6 & 0.526 & 259 & 48 & 0.48 & 0.442 \\
\hline $\mathrm{CC}$ & 111 & 35.6 & 0.356 & 208 & 38.6 & 0.386 & 0.442 \\
\hline $\mathrm{C}$ & 386 & 61.9 & 0.619 & 337.5 & 62.6 & 0.626 & 0.398 \\
\hline A & 238 & 38.1 & 0.381 & 201.5 & 37.3 & 0.373 & 0.398 \\
\hline \multicolumn{8}{|c|}{ IL-18 SNP (-137 G/C) } \\
\hline $\mathrm{CC}$ & 26 & 8.3 & 0.083 & 37 & 6.9 & 0.069 & 0.720 \\
\hline CG & 125 & 40.1 & 0.401 & 216 & 40 & 0.40 & 0.720 \\
\hline GG & 161 & 51.6 & 0.516 & 286 & 53.1 & 0.531 & 0.720 \\
\hline G & 447 & 71.6 & 0.716 & 394 & 73.1 & 0.731 & 0.275 \\
\hline $\mathrm{C}$ & 177 & 28.4 & 0.284 & 145 & 26.9 & 0.269 & 0.275 \\
\hline \multicolumn{8}{|c|}{ IL-18 SNP (-133 C/G) } \\
\hline $\mathrm{CC}$ & 150 & 48.1 & 0.481 & 281 & 52.1 & 0.521 & 0.519 \\
\hline CG & 130 & 41.6 & 0.416 & 206 & 38.2 & 0.382 & 0.519 \\
\hline GG & 32 & 10.3 & 0.103 & 52 & 9.7 & 0.97 & 0.519 \\
\hline $\mathrm{C}$ & 430 & 68.9 & 0.689 & 384 & 71.2 & 0.712 & 0.168 \\
\hline $\mathrm{G}$ & 194 & 31.1 & 0.311 & 155 & 28.8 & 0.288 & 0.168 \\
\hline
\end{tabular}

However, the frequencies of combined IL-18 genotypes arising by the combinations of the three examined common polymorphisms in this gene were significantly different between both groups $\left(P=0.009, P_{\text {corr }}<0.05\right.$, OR $=5.35,95 \%$ CI: 1.9-15.2) (see Table 4).

Finally, we analyzed the relationship of all polymorphic variants with intermediary phenotypes of atopy. We found a marginal association of serum $\operatorname{IgE}$ levels with SNP at position $-607(P=0.05)$. Rhinitis patients homozygous for $-607 \mathrm{~A}$ allele had higher $\mathrm{IgE}$ levels $(400 \pm 785.9 \mathrm{kU} / \mathrm{ml}$, mean $\pm \mathrm{SD})$ in comparison with heterozygotes $(202.9 \pm 333.3 \mathrm{kU} / \mathrm{ml})$ and homozygotes for C allele $(219.7 \pm 360.6 \mathrm{kU} / \mathrm{ml})$ (see Fig. 1). Figure 2 presents an evaluation of the skin prick test (negative vs. positive for the fungus Alternaria sp.) in AR patients. When allergic patients were subdivided in two groups (subjects with positive and those with negative skin prick test for $A$. alternata), the IL-18 $607 \mathrm{~A} / \mathrm{C}$ polymorphism was significantly associated $(P$ $=0.0037, P_{\text {corr }}<0.05$ for allele differences, $P=0.0021$, $P_{\text {corr }}<0.05$ for phenotype differences) with a positive reactivity to this allergen. The same comparison was
Table 4 IL-18 genotype combinations in both groups ( $\chi^{2}$ test was used for comparison of differences in genotype combinations among groups)

\begin{tabular}{lrrr}
\hline $\begin{array}{l}\text { Genotypes combinations } \\
-607 \text { C/A, }-137 \mathrm{G} / \mathrm{C},\end{array}$ & $\begin{array}{l}\text { Control } \\
(n=312)\end{array}$ & $\begin{array}{l}\text { Allergic } \\
\text { rhinitis } \\
(n=539)\end{array}$ & \\
\hline AACCCC & 2 & 4 & \\
AACCCG & 1 & 3 & \\
AACCGG & 16 & 28 & \\
AACGCC & 0 & 4 & \\
AACGCG & 16 & 27 & \\
AACGGG & 0 & 2 & \\
AAGGCC & 1 & 4 & \\
AAGGGG & 1 & 0 & \\
ACCCGG & 7 & 2 & \\
ACCGCC & 4 & 35 & \\
ACCGCG & 98 & 137 & \\
ACCGGG & 7 & 11 & \\
ACGGCC & 44 & 65 & \\
ACGGCG & 3 & 7 & \\
ACGGGG & 1 & 2 & \\
CCGGCC & 99 & 169 & \\
CCGGCG & 12 & 32 & \\
CCGGGG & 0 & 7 & \\
\hline
\end{tabular}


performed for other antigens: house dust mites ( $D$. pteronyssinus, $D$. farinum), but no association was found (data not shown). Allergens other than A. alternata, D. pteronyssinus and D. farinae were not possible to use for analysis of their association with genotype IL-18 polymorphisms because most of the patients showed a positive reaction to them. Similarly in cases where the data file contains only a few negative or positive results (against the opposite group), it is not possible statistically to evaluate a relationship between genotype and phenotype, in other words to show a positivity or negativity with the skin prick tests. The results of these tests were, of course, used as diagnostic markers of allergic sensitization.

\section{Discussion}

The pathogenesis of allergic diseases remains poorly understood, and it is now seen as a complex interplay between environmental factors and a host response, often modified by behavioural factors. A number of candidate genes have been proposed, and many regions have been identified that show evidence for linkage to allergic diseases.

In this study we have investigated the association of three different promoter SNPs of the IL-18 gene (-607 $\mathrm{C} / \mathrm{A},-137 \mathrm{G} / \mathrm{C}$ and $-133 \mathrm{C} / \mathrm{G})$ with $\mathrm{AR}$, including concomitants of other atopic diseases such as asthma and eczema, or both. Although no genotype or allele frequencies of particular SNPs of the IL-18 gene were statistically significantly different between allergic and control subjects, a combination of all three promoter polymorphisms was related to $\mathrm{AR}$ in the population examined. In addition, A allele of the IL-18 -607 polymorphism was associated with an intermediary phenotype of allergy, such as positivity to skin prick tests for the fungus Alternaria sp. There is much documented research demonstrating the relationship between fungal sensitization and AR and asthma (Arshad et al. 2001), as well as a growing volume of literature on data linking fungal exposure to asthma and rhinitis exacerbation in sensitized children (Halonen et al. 1997; Nolles et al. 2001; Stark et al. 2005).

Why the association between $-607 \mathrm{C} / \mathrm{A}$ and the skin prick test results are only significant for Alternaria and not for any of the other allergens studied is not known. The mold-allergen extracts used for the skin test depend on the prevalence of various molds in the region, as identified with annual atmospheric sampling. As already mentioned, Alternaria sp. is a common mold allergen source in the Czech Republic, and for this reason the positivity test for Alternaria sp. was involved in the standard skin prick test in our study. However, in the literature, antigenic $[\mathrm{Ag}]$ determinants have been reported among some mold species, as observed in the closely related genera Alternaria and Stemphyllium, and the allergic immune response is believed to begin with the processing of mold Ags by Ag-presenting host dendritic cells. Dendritic cells present the mold allergen to type 2 T-helper (Th2) cells, which then differentiate into the effector stage and produce Th2 cytokines (interleukin [IL]-4, IL-5, and IL-13). IL-4 is essential for isotype switching to IgE, and with additional signaling provided by the Th2 cells with cognitive interaction, $\mathrm{B}$ cells begin to produce $\operatorname{IgE}$ specific
Fig. 1 Statistical evaluation of the total $\mathrm{IgE}$ levels in allergic rhinitis $(A R)$ patients and in controls. Nonparametric Kruskal-Wallis ANOVA $(P<0.05)$

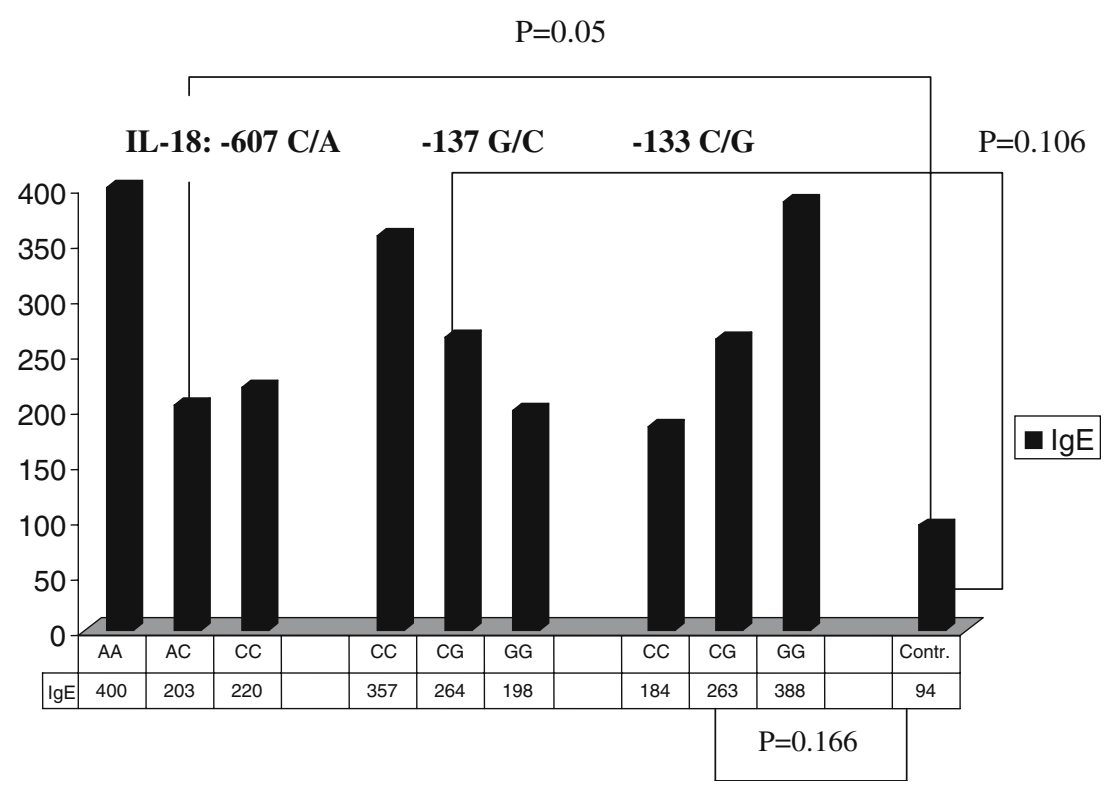


Fig. 2 Evaluation of the skin prick test (negative vs. positive for the fungus Alternaria sp.) in AR patients versus genotypes of IL-18 variants [*Note-numbers 0 , $1,2,3$ and 4 express the level of the positivity test, where 0 $=$ negative and $4=$ the most strong; $P 1$ value: Fisher exact test (for allele differences); $P 2$ value: Fisher exact test (for phenotype comparisons), Fisher exact test: ALT 0 versus ALT 1-4]

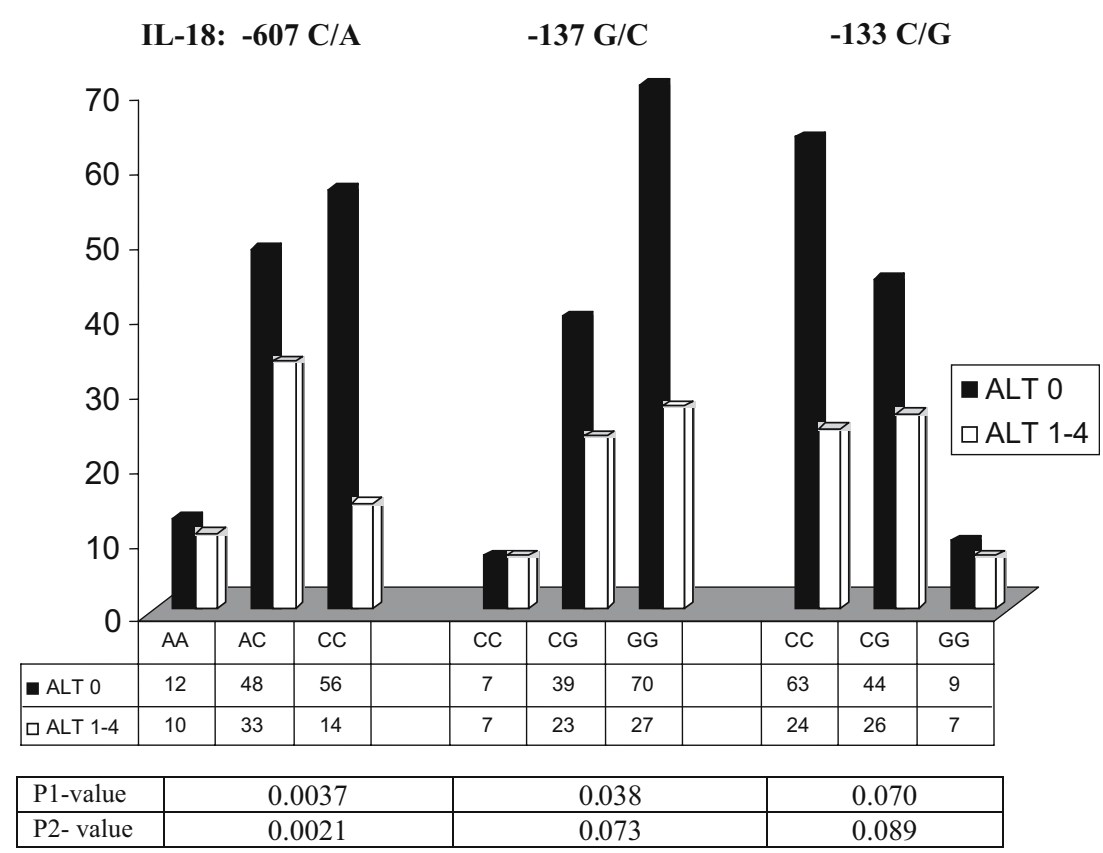

for allergens. Since our study shows a marginally significant association of the IL-18-607 variant with IgE levels $(P=0.05)$ in patients, it is consistent with the aforementioned facts that patients allergic to Alternaria (according to the skin prick test and positive reactivity to this allergen), but not those allergic to other antigens such as the house dust mites examined, showed a significant association with the IL-18-607 polymorphism.

Novak et al. (2005) demonstrated the highest association with AE relating to SNP $-137[\mathrm{~g} / \mathrm{c}]$ located in the GATA3 binding site of the IL-18 gene, which has been shown to be strongly involved in Th2 differentiation. Most interestingly, the highest frequency of this polymorphic allele has been detected in patients with the intrinsic and non-atopic subtype of $\mathrm{AE}$, indicating a role for this SNP in the development of a GATA3dependent $\mathrm{TH} 2$ predominance, especially in patients with low serum IgE levels without any sensitizations.

Krusse et al. (2003) confirmed that previously identified SNP in promoter $1(-137[\mathrm{~g} / \mathrm{c}]$, GATA3 site) of the IL18 gene was significantly associated with high $\mathrm{IgE}$ levels and specific sensitization. In addition, they also demonstrated that another SNP of the IL-18 gene located in promoter $2(-133[\mathrm{c} / \mathrm{g}]$; nuclear factor 1 site $)$ was related to these intermediary phenotypes. In our study the total serum IgEs were only marginally associated with IL-18 -607 C/A polymorphism in rhinitis patients.

One of the most recent studies (Lee et al. 2006) in this field shows that the A allele in the IL-18/-607 $(\mathrm{C} / \mathrm{A})$ gene promoter region may be involved in the development of AR in the Korean population. From the results of our study of Czech patients it is possible to conclude that at least the $-607 \mathrm{C} / \mathrm{A}$ variant may play an important role in the etiopathogenesis of AR in a Czech population. Clearly, indications that polymorphisms in the IL-18 gene might modulate susceptibility to rhinitis or other allergies warrant further attention and investigation. Our results suggest that a combination of the IL-18 gene promoter variants $(-607 \mathrm{C} / \mathrm{A}$, $-137 \mathrm{G} / \mathrm{C}$ and $-133 \mathrm{C} / \mathrm{G}$ ) may be one of the factors that participates in the pathogenesis of AR or its intermediary phenotypes.

Acknowledgments We thank Dr. Helena Melicharova, Dr. Jana Teturova, Dr. Alexandra Pazdirkova, Dr. Vincent Izakovic, Dr. Iveta Nemcova, Dr. Lenka Siskova, Dr. Ondrej Rybnicek, Dr. Bronislava Novotna and Dr. Dana Buckova for help in the recruitment of patients from different allergologic clinics and from outpatient clinics of general practitioners in the Czech Republic. We also appreciate the help of Ms. Marketa Mimova for laboratory assistance. This work was supported in part by postdoctoral grant no. 305/03/D195 from the Grant Agency of the Czech Republic.

\section{References}

Arshad SH, Karmaus W, Matthews S, Mealy B, Dean T, Frischer T, Tsitoura S, Bojarskas J, Kuehr J, Forster J (2001) SPACE study group (study of prevention of allergy in children of europe) association of allergy-related symptoms with sensitisation to common allergens in an adult European population. J Invest Allergol Clin Immunol 11:94-102

Beasley R (1998) Worldwide variation in prevalence of symptoms of asthma, allergic rhinoconjunctivitis, and atopic eczema: ISAAC. The international study of asthma and 
allergies in childhood (ISAAC) Steering Committee (1998) Lancet 351:1225-1232

Buckova D, Holla LI, Vasku A, Znojil V, Vacha J (2002) Lack of association between atopic asthma and the tumor necrosis factor alpha-308 gene polymorphism in a Czech population. J Invest Allergol Clin Immunol 12:192-197

Halonen M, Stern DA, Wright AL, Taussig LM, Martinez FD (1997) Alternaria as a major allergen for asthma in children raised in a desert environment. Am J Respir Crit Care Med 155:1356-1361

Hanifin JM, Rajka G (1980) Diagnostic features of atopic dermatitis. Acta Derm Venereol (Stockh) 92:44-47

Imboden M, Nicod L, Nieters A, Glaus E, Matyas G, Bircher AJ, Ackermann-Liebrich U, Berger W, Probst-Hensch NM, APALDIA Team (2006) The common G-allele of interleukin-18 single-nucleotide polymorphism is a genetic risk factor for atopic asthma. The SAPALDIA Cohort Study. Clin Exp Allergy 36:211-218

Izakovicova Holla L (2003) Interleukin-18 in asthma and other allergies. Clin Exp Allergy 33:1023-1025

Kalina U, Ballas K, Koyama N, Kauschat D, Miething C, Arnemann J, Martin H, Hoelzer D, Ottmann OG (2000). Genomic organization and regulation of the human interleukin-18 gene. Scand J Immunol 52:525-530

Koppelman GH, Stine OC, Xu J, Howard TD, Zheng SL, Kauffman HF, Bleecker ER, Meyers DA, Postma DS (2002) Genome-wide search for atopy susceptibility genes in Dutch families with asthma. J Allergy Clin Immunol 109(3):498-506

Kruse S, Kuehr J, Moseler M, Kopp MV, Kurz T, Deichmann KA, Foster PS, Mattes J (2003) Polymorphisms in the IL 18 gene are associated with specific sensitization to common allergens and allergic rhinitis. J Allergy Clin Immunol 111:117-122

Lee HM, Park SA, Chung SW, Woo JS, Chae SW, Lee SH, Kang HJ, Hwang SJ (2006) Interleukin-18/-607 gene polymorphism in allergic rhinitis. Int $\mathrm{J}$ Ped Otorhinol 70:1085-1088

Nakanishi K, Yoshimoto T, Tsutsui H, Okamura H (2001) Interleukin-18 regulates both Th1 and Th2 responses. Annu Rev Immunol 19:423-474

NHLBI/WHO (2002) Global strategy for asthma management and prevention. Global initiative for asthma. NIH publication no. 01-3659

Nolles G, Hoekstra MO, Schouten JP, Gerritsen J, Kauffman HF (2001) Prevalence of immunoglobulin E for fungi in atopic children. Clin Exp Allergy 31:1564-1570

Novak N, Kruse S, Potreck J, Maintz L, Jenneck C, Weidinger S, Fimmers R, Bieber T (2005) Single nucleotide polymorphisms of the IL18 gene are associated with atopic eczema. J Allergy Clin Immunol 115:828-833

Skoner DP (2001) Allergic rhinitis: definition, epidemiology, pathophysiology, detection, and diagnosis. J Allergy Clin Immunol 108(1 Suppl):2-8

Stark PC, Celedon JC, Chew GL, Ryan LM, Burge HA, Muilenberg ML, Gold DR (2005) Fungal levels in the home and allergic rhinitis by 5 years of age. Environ Health Perspect 113:1405-1409

Van Bousquet J, Cauwenberge PN, Khaltaev N (2001) Allergic rhinitis and its impact on asthma. ARIA workhop report. J Allergy Clin Immunol 108:148-333 